\title{
O CONCEITO DE POLITIZAÇÃO DA MATERNIDADE COMO LEGADO DE PESQUISA
}

\author{
Maria Simone Vione Schwengber* \\ Carin Klein**
}

Resumo: O artigo aborda argumentos engendrados por Meyer (2003; 2005; 2006; 2009) sobre o conceito de politização da maternidade. As disputas em torno da maternidade no século XXI ocorrem marcadas pelo fortalecimento dos feminismos e em resposta ao adensamento de algumas práticas culturais e políticas que operam com recursos econômicos, simbólicos e educativos em alguns eixos: o controle sobre os corpos das mulheres, a maternidade e o lugar do Estado. Apresentamos análises decorrentes de duas pesquisas de doutorado, uma com foco nas responsabilidades individuais de uma politização da maternidade e outra voltada para a responsabilização coletiva pela via das políticas de inclusão social. A primeira examina a politização do corpo grávido, e a outra discute a politização da maternidade no âmbito de políticas públicas brasileiras, sobretudo, no Primeira Infância Melhor/RS.

Palavras-chave: Politização da maternidade; gênero e educação.

\section{THE CONCEPT OF POLITICIZATION OF MOTHERHOOD AS A RESEARCH LEGACY}

\begin{abstract}
This paper approaches arguments engendered by Meyer $(2003 ; 2005 ; 2006 ; 2009)$ about the concept of politicization of motherhood. Discussions about $21^{\text {st }}$ century motherhood have been marked by the strengthening of feminisms, and in response to the densification of some cultural and political practices operated through economical, symbolical and educative resources in some axes: the control over women's bodies, motherhood, and the place of the State. We present analyses derived from two doctoral researches: one with a focus on the individual responsibilities of the politicization of motherhood, and the other concentrated on the collective accountability through social inclusion policies. The first one examines the politicization of the pregnant body, and the second discusses the politicization of motherhood in the sphere of Brazilian public policies, especially in the Program known as Better Early Childhood Development/RS.
\end{abstract}

Keywords: Politicization of motherhood; gender and education.

Submissão 20-11-18 Aceite 16-05-19

\section{INÍCIO DE CONVERSA}

Participar de um dossiê que se propõe a homenagear o Grupo de Estudos de Educação, Sexualidade e Relações de Gênero (GEERGE), da Universidade Federal do Rio Grande do Sul (UFRGS), constitui-se como um tributo desafiador, pois se trata de destacar um grupo "não tradicional” que abraça, amplia, aprofunda temas, objetos e questões de pesquisa de relevância social academicamente ainda pouco explorados, em geral jogados nos interstícios do silêncio. Boa parte dos esforços realizados pelo Grupo está centrada no desafio de pensar a educação, as lutas cotidianas por igualdade, a produção de sentidos, as relações pedagógicas contemporâneas, a valorização da solidariedade em detrimento da competição, a ênfase e o exame dos processos de produção da diferença e do não preconceito.

\footnotetext{
* Doutorado em Educação - UFRGS. Professora do Programa de Pós-Graduação em Educação nas Ciências da Universidade Regional do Noroeste do Estado do Rio Grande do Sul.

*** Doutorado em Educação - UFRGS. Professora adjunta do Programa de Pós-Graduação em Educação da Universidade Luterana do Brasil
} 
O GEERGE/UFRGS, ao longo de sua existência, tem se preocupado em contribuir com a promoção de uma cultura política democrática, capaz de dar lugar à pluralidade de pontos de vista e à multiplicação dos olhares e lugares de fala, assim dando visibilidade para a teorização e a reflexão sobre os processos que envolvem as relações sociais. Destacamos aqui nosso orgulho em participar dessa experiência formativa - do honroso e gratificante privilégio de pertencer a esse grupo de estudos. Um grupo que se caracteriza pela combinação de rigor, afeto e pesquisa e que tem contribuído sobremaneira para a formação de muitos profissionais e pesquisadores em nosso país.

Neste artigo, escolhemos evidenciar alguns aspectos das pesquisas produzidas por nós no âmbito da linha de pesquisa Educação, Sexualidade e Relações de Gênero, sobretudo, a partir da discussão desenvolvida por Dagmar Meyer sobre o conceito de politização da maternidade. Compreendemos que tais produções trouxeram significativas contribuições e visibilidade acadêmica e científica ao GEERGE/UFRGS, bem como aos nossos processos particulares de formação na pós-graduação em Educação na UFRGS.

Escolhemos iniciar este texto recordando as palavras de Meyer (2003) ao dizer: "comece tecendo o texto". Desse modo, cada discussão pode ser pensada como um fio; cada fio tem uma cor, e podemos tecer diferentes combinações, tal como uma tecelã (autora), que tramará os fios de determinados modos, e não de outros. Então, para melhor destacar esses modos de organização do texto, inicialmente, apresentamos alguns elementos centrais do conceito de politização da maternidade, para depois evidenciarmos como tal conceito operou (e vem operando) a partir dos desdobramentos desenvolvidos por duas pesquisas.

\section{A POLITIZAÇÃO DA MATERNIDADE}

Meyer (2003; 2005; 2006; 2009), ao longo de suas pesquisas, foi cunhando, ou melhor, circunscrevendo a tese sobre a "politização do feminino e da maternidade". Meyer (2003) faz um recuo no tempo, assinalando que a função maternal não era objeto de tamanha atenção e valorização, como se tornou nas sociedades ocidentais contemporâneas. Segundo a autora (2006), essa situação começa a alterar-se apenas na modernidade, quando se opera uma espécie de mudança das mentalidades, o que permitiu a emergência de novos sentidos, tal como: o de que a maternidade equivale 
à saúde da gestação biológica e dela decorre, o que está circunscrito de modo particular ao corpo da mulher.

Os sentidos circunscritos ao corpo (dimensão biológica) da mulher foram pouco a pouco produzidos em um período e contexto histórico específicos da modernidade: aquele em que a vida biológica, de modo geral, e os corpos das crianças, em particular, entraram na história das sociedades ocidentais, ou seja, quando a população (e, dentro desta, a infância) entrou na ordem do saber e do poder - um período que Foucault (1993, p. 131) denominou de "era do biopoder".

Meyer (2003) apoia-se nos estudos de Foucault (1993) e de Yalom (1997), que indicam os séculos XVIII e XIX como períodos de substantivas transformações sociais, econômicas, científicas e políticas nas quais os corpos, em especial, os das mulheres e, mais especificamente, o seio feminino e o aleitamento materno - a maternidade - foram “politizados". Meyer (2003) qualifica inicialmente a politização referindo-se à centralidade dada à maternidade, colocada no foco de processos e estratégias educativas destinadas ao controle da saúde dos corpos das mulheres; pouco a pouco, tais estratégias foram sendo implementadas com a finalidade de tornar esses corpos mais produtivos e menos ameaçadores à sociedade, já que seriam as "fontes" primeiras da saúde e do vigor da população. Nesse movimento, tanto os corpos das mulheres quanto o seio feminino e o aleitamento materno, que era, em outros tempos, uma dimensão de ação da esfera privada, expandem-se e passam a interessar, crescentemente, não mais apenas às mulheres e ao grupo familiar, mas também ao Estado.

Meyer (2003) ajuda-nos a entender como se articulou na Europa, a partir da modernidade, um conjunto de acontecimentos, tais como: 1) as campanhas para abolir o arraigado e difundido costume da aristocracia e da burguesia emergente de entregar as crianças para serem criadas por amas-de-leite; 2) a necessidade dos estados nacionais nascentes de expandir sua população para atender às suas crescentes demandas militares e econômicas; 3) a instauração e legitimação da autoridade médica, o que, no contexto de reestruturação das políticas de reprodução humana vigentes, levaria à substituição das parteiras pelos médicos (homens); 4) a emergência e consolidação de um movimento intelectual e político que, no âmbito do Iluminismo, congregou filósofos, médicos, escritores políticos e funcionários de governo, assinalando o “o corpo feminino" como responsável pela procriação.

Configura-se, assim, a partir da modernidade, um novo estatuto para a maternidade, a partir do qual (e em função do qual) "os deveres familiares e maternos 
se tornaram importantes assuntos do Estado e de ações/programas políticos" (MEYER, 2003, p. 13). No Brasil, foram fundamentalmente os saberes da medicina que iniciaram o processo de maternalização, contando com o apoio do Estado, como salienta Meyer (2003). Para o aparato médico sanitário, as mulheres mães eram consideradas seres frágeis, quando não inferiores, "ignorantes e negligentes"; por isso, elas precisavam de conselhos e da popularização de ensinamentos constantes dos profissionais da saúde, particularmente no que se referia às formas de viver e pensar o processo de condução e implementação da reprodução biológica e social ${ }^{1}$.

Meyer (2006) aponta que, para assegurar a materialidade da relação mãe-filho/a, as ações no Brasil se desenvolveram em dois sentidos: primeiro, empreendendo-se campanhas contra mortalidade infantil, aborto, infanticídio, abandono de crianças; segundo, buscando-se transformar as mães, bem como seus hábitos, comportamentos e sentimentos com relação aos/às filhos/as. Nesse sentido, tratar da educação das mães torna-se um imperativo (uma civilidade para com a nação), que deveria/deve ser organizado e desenvolvido em instituições como hospitais, institutos de puericultura e lactários.

Essas ações para educar as mães geravam certa tensão, pois contradiziam as noções de uma suposta "natureza" maternal, feminina e instintiva. Para Meyer (2006, p. 14), a história mostra que, "em vez de instinto maternal, seria melhor falar de uma fabulosa pressão social educativa que a sociedade moderna e contemporânea disponibilizou para que a mulher aprendesse a se relacionar e cuidar dos filhos". Assim, um conjunto de discursividades passou a posicionar a mulher (categoria então essencializada e universalizada) como sendo, por natureza, uma criatura generosa, abnegada e instintivamente mãe, disposta a qualquer sacrifício por sua cria.

Ao longo do século XX, a sociedade ocidental promoveu uma individualização da maternidade, produzindo a figura da mãe responsável, tanto pelas práticas de saúde, da puericultura e da educação da infância, quanto pelas práticas simbólicas mediante investimento no crescimento do sentimento maternal (MEYER, 2003). Erige-se, aí, a figura da mãe como aquela que dá "o amor a mais", a vida, o alimento, as primeiras e contínuas socializações e a educação. A incorporação desses discursos requeria um novo modelo feminino: "mãe cuidadosa é aquela que cuida e se cuida" (SCHWENGBER, 2006, p.110) aquela que deve estar sempre atenta à sua saúde

\footnotetext{
${ }^{1}$ Sobretudo sob um viés médico e psicologizante, disseminam-se, a partir da década de 50, programas de rádio, livros e matérias em revistas em que teóricos como John Bolby e Donald Winnicott se tornam precursores de modelos educativos voltados para a construção de uma determinada "maternidade", cuja ênfase se concentra no papel único e insubstituível da mãe no desenvolvimento emocional da criança.
} 
e à dos membros da família. Responsável pelos mínimos detalhes que possam comprometer o bom andamento da saúde da família, a mulher mãe deve ser vigilante, abnegada, afetuosa, assexuada, frágil enquanto mulher, mas forte e saudável enquanto mãe e soberana dentro do lar (MEYER, 2003).

Os investimentos na posição de mãe cuidadosa representaram uma transformação importante - em parte, produzida pelo novo modelo de família contemporânea. Essa posição de mãe não só atribuiu outra função à mulher, como também reformulou as relações familiares: o elo clássico e o poder paterno (pai-filho/a) desviavam-se para o inalienável binômio mãe-filho/a. Meyer (2009, p. 18) assinala que, a partir do século XX, ocorreu um "declínio do poder paternal", com o "maior controle das mulheres sobre a criação de filhos referindo-se a um deslocamento da autoridade paternal para a afeição maternal". A autora (2006) afirma que, agregado a esse posicionamento, se tornou fundamental o investimento na educação de tarefas vistas como próprias do feminino, associadas com as ações de parir, gestar, cuidar, educar e amar.

\section{A POLITIZAÇÃO DO CORPO GRÁVIDO}

Instigadas pelas referências teóricas de Meyer, identificamos processos de politização da maternidade que não só prosseguem com seus cursos contemporaneamente, mas ocorrem ao se complexificarem e se expandirem na direção de ampliar sentidos em torno da politização, que atinge de modo particular os corpos grávidos na contemporaneidade. A partir dos elementos destacados sobre a politização da maternidade, examinada por Meyer (2003; 2005; 2006; 2009), emerge nosso interesse pela problemática, pensando a politização dos corpos grávidos no contexto de um artefato específico da mídia impressa brasileira, a revista Pais \& Filhos ${ }^{2}$.

Rosa Fischer (2002) é uma das estudiosas que chamam a atenção para a importância que a mídia assume ao ocupar uma posição central no processo de constituição do sujeito contemporâneo, nos modos de ser homem e mulher, e inclusive nos de ser pai, mãe e gestante. Seduziu-nos o desafio de compreender como um artefato específico da mídia brasileira, a Pais \& Filhos, contribuiu para a reprodução e veiculação de discursos implicados com a politização de corpos grávidos na contemporaneidade.

\footnotetext{
${ }^{2}$ SCHENGBER, Maria Simone Vione. Donas de si? A educação de corpos grávidos no contexto da Pais \& Filhos. Tese (Doutorado em Educação) - Programa de Pós-Graduação em Educação, Faculdade de Educação, Universidade

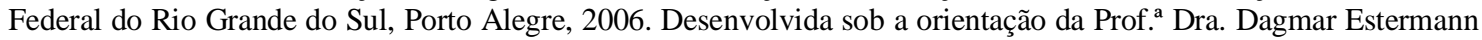
Meyer, na Linha de Pesquisa Educação, Sexualidade e Relações de Gênero.
} 
Examinamos exemplares $^{6}$ da revista publicados no período de 1968 a 2005, perfazendo um total de 674 revistas, o que nos permitiu dar conta da análise de quase quatro décadas de existência da publicação (SCHWENGBER, 2006). Procuramos garantir ao menos duas ou três edições de cada ano de publicação, desde o lançamento da Pais \& Filhos. Uma vez que cada época diz o que pode dizer, conforme suas condições de enunciação e seus campos de visibilidade (FOUCAULT, 1998), desafiamo-nos, com esse exame, a compreender a maternidade e, principalmente, a gravidez sob o prisma desse contexto histórico.

No contexto da mídia brasileira direcionada à família e, sobretudo, às mulheres (potencialmente) mães, ressaltamos a importância da Pais \& Filhos, uma vez que essa publicação é tida como "a mais tradicional revista da família brasileira, há cinquenta anos no mercado" (MIRA, 2001, p. 41). A revista desfruta de uma longevidade notável, comparada com a quantidade considerável de revistas lançadas para esse público a cada ano no Brasil ${ }^{7}$, ainda mais se considerarmos que poucas delas conseguem passar pela prova dos 10 anos da primeira publicação.

\section{PAIS \& FILHOS E A EDUCAÇÃO DOS CORPOS GRÁVIDOS}

$\mathrm{Na}$ contemporaneidade, as revistas fazem parte de um aparato discursivo e ocupam um lugar importante de mediadores culturais. Destacamos a Pais \& Filhos como uma, dentre muitas, das tradutoras dos discursos técnico-científicos (em especial, os de gestão e promoção da saúde) para o senso comum.

Observa-se, na contemporaneidade, uma frutífera aliança entre mídia e os cuidados corporais (FISCHER, 2002). Percebe-se a emergência de uma forma de saber-poder, a informação, que adverte os indivíduos sobre os riscos, tendo em vista o que fazem e o que trazem como herança. Podemos dizer que a contemporaneidade monitora os corpos mediante as informações, dentro daquilo que Fraga (2005, p. 28) chamou de uma "biopolítica informacional": "[...] uma forma de governo que não depende [apenas] da relação corpo-a-corpo para fazer valer um poder sobre a vida da espécie, mas de um conjunto de técnicas, procedimentos e saberes que regulam a vida por meio das informações".

Passamos, pois, a salientar aqui alguns dos cuidados corporais pelos quais a Pais \& Filhos nos educa como sujeitos de gênero. Entendemos que educar mulheres grávidas, com foco em seus corpos, está dentro dos processos de politização 
que nos educam como mulheres, uma vez que, está dentro dos processos de politização que nos educam como mulheres, ensinando-nos, nesse caso, a conferir sentidos à gravidez e à maternidade, em um processo que não é linear, nem homogêneo, tampouco está acabado e completo (MEYER, 2003).

Observamos, na revista", um movimento que nos apresenta, em uma "nova" história, formas de relacionamento e gerenciamento de corpos na gravidez (SCHWENGBER, 2006). Um dos efeitos da estratégia de investimentos nos corpos grávidos elaborada pela revista é a definiçãa de diferentes posições de sujeito, pois estar gestante e tornar-se mãe não são, nesse contexto, a mesma coisa que ser mulher. É possível afirmar que a Pais \& Filhos faz um declarado movimento no sentido de posicionar a mulher gestante, diferenciando-a da posição de sujeito mulher (SCHWENGBER, 2006).

Podemos afirmar que a noção de mulher-mãe-gestante com a qual a revista parece operar é a de um ser que incorpora múltiplos seres e que neles se (des)faz. Isso ocorre quando a revista recomenda, por exemplo, que as gestantes sejam, ao mesmo tempo, nutricionistas, psicólogas, esteticistas e especialistas em desenvolvimento fetal e façam consultas e exames médicos regularmente durante a gravidez. ${ }^{10}$ Elas são desafiadas a colocar seus corpos (e os cuidados corporais a eles relacionados) à frente de qualquer outra necessidade. Em movimentos como esse, vemos desenhar-se, nas páginas da Pais \& Filhos, uma imagem de mãe com características de mulher-ativa-com-um-corpo-bem-cuidado, instigada a fazer o melhor de si por si mesma e pelo feto/filho/a (SCHWENGBER, 2006).

De modo geral e de maneira muito direta, leitoras e leitores da revista convivem com o princípio de que um corpo grávido "deve" ser cuidado e "aperfeiçoado" (PAIS \& FILHOS, 1990, p. 18). Nessa perspectiva, observa-se que a gravidez vai sendo definida, ao longo do projeto editorial da revista, como uma condição devidamente "controlada, regulada, plena de temperança, prudência, gestão criteriosa/ponderada dos riscos" (PAIS \& FILHOS, 1990, p. 14). Ao contrário das "antigas" mães, que, segundo Schwengber (2006), "mal tomavam conhecimento" dos seus corpos e dos cuidados com os/as filhos/as, as "novas" mães, em especial as de classe média"1 , têm sido convocadas a tornarem-se as maiores consumidoras dos discursos de perfectibilidade física dos corpos. A contemporaneidade deixa de ser um tempo de descuido com os corpos especialmente para as mulheres - para ser um tempo protocolar de correções físicas da aparência e da saúde. 
Entendemos que os discursos de completo bem-estar físico, mental e social, oriundos do próprio conceito da Organização Mundial da Saúde (OMS) e (re)afirmados particularmente pela medicina americana, mudaram o perfil dos modos de relacionarmo-nos com os corpos e com a saúde. Observa-se claramente que a saúde materna também se inspirou nessa enunciação da OMS, investindo no completo bem-estar. Esse conceito de saúde tem como referência um modelo de saúde idealizado a ser alcançado - a saúde perfeita -, cujas características holísticas (a completude inatingível) servem como padrão também para definir aspectos específicos da saúde materna. Tal representação sustenta a existência de um estado ótimo de saúde como critério de avaliação dessa saúde materna. Nessa perspectiva, a condição de pleno "bem-estar" seria assegurada somente por meio do uso adequado dos recursos das ciências.

Pensamos que pressupostos como esses produzem efeitos na educação e regulação das grávidas na contemporaneidade, redimensionando a relação corpo $x$ gestante $x$ feto, ao mesmo tempo em que ensinam às gestantes, conforme Schwengber (2006, p. 142), que "é preciso adquirir e aperfeiçoar [a saúde] antes, durante e depois da gravidez".

Nas páginas da Pais \& Filhos, fala-se da condução de uma gravidez "planejada". Ressaltamos que a compreensão de que uma gravidez deve ser rigorosamente planejada acaba por exigir das mulheres-gestantes - e só de cada uma delas - um engajamento individualizado, principalmente com o dever de ter, controlar, promover e aperfeiçoar a saúde (SCHWENGBER, 2006). Isso implica posicionar na esfera individual a responsabilidade pelos meios e recursos necessários para a viabilização do projeto de corpo (o da gestante e o do feto) e de saúde da sociedade, como observa Meyer (2002).

Desse modo, vemos que as gestantes ${ }^{12}$ são chamadas pela revista para

administrar seus riscos, numa forma de autopoliciamento privado que implica o dever de lutar contra o próprio destino, ultrapassando os limites da própria configuração biológica com a ajuda da tecnociência [para alcançar] o imperativo da saúde controlada/perfeita, no campo da procriação, na tentativa de evitar que erros inscritos como probabilidades nos códigos genéticos se efetivem - tanto nos organismos quanto no corpo social (SIBILIA, 2004, p. 199).

O "inimigo" número um de uma gravidez saudável, que aparece nos múltiplos discursos veiculados pela Pais \& Filhos, é o próprio corpo das gestantes ${ }^{13}$, pois é ele que é preciso "limpar, evidenciar, analisar" (SCHWENGBER, 2006, p. 140). 
O fato de a mulher estar grávida modifica quase completamente o olhar que se tem sobre o seu corpo, o que se pode ver, por exemplo, quando a Pais \& Filhos afirma, já na década de 70, que "cada gestante deve aprender a decodificar, incessantemente, as linguagens de um organismo grávido, valendo-se, para isso, do pré-natal"14 (Pais \& Filhos, 1974, p. 35). A revista multiplica e faz circular o enunciado, que continua sendo constantemente atualizado e ampliado por outros discursos de que um

bom pré-natal é a linha divisória entre a vida e a morte, a saúde e a doença, a normalidade e a anormalidade, [e] o que interessa é que isso é dito às mulheres, frequentemente, e que são elas que precisam cuidar de seus corpos grávidos e dos corpos de seus filhos (RIPOLL, 2005, p. 66).

É possível dizer que, a partir de 1990, a discussão sobre a saúde do feto alcançou um nível de detalhamento sem precedentes nas páginas da Pais \& Filhos, devido à introdução de inúmeros artigos sobre o desenvolvimento e o uso de novas tecnologias, tais como o ultrassom e a amniocentese. Tais tecnologias possibilitaram a visualização e a individualização do feto, separando-o precocemente ${ }^{15}$ da mãe. O feto, a partir dessas inovações tecnológicas, saiu do domínio da experiência privada para o domínio público, passando a ser objeto de visualização, externalização, vigilância, regulação (LUPTON, 1999). Meyer e Soares (2004, p. 10) observam que, nas culturas ocularcêntricas, as diversas tecnologias científicas, mediante as técnicas de observações e registros, ajudam de um modo especial a "[...] instituir e promover determinadas posições de sujeito como adequadas em oposição a outras, consideradas impróprias e desviantes". Entendemos que as imagens das ecografias, na revista, não se apresentam apenas como recurso técnico visual, dando também respostas a questões ligadas ao que Louro (2004) denomina de códigos identitários, pois, ao observar-se o feto, avaliá-lo, medi-lo, classificá-lo, se produzem divisões, distinções e, ainda, nomeações de gênero. Trata-se de um processo duplo que classifica mãe e feto, porque inscreve marcas nos dois corpos: anormais/normais, saudáveis/doentes, negligenciados/cuidados.

A Pais \& Filhos incita-nos a pensar em uma dupla e concomitante operação: uma que entroniza as mães em sua missão sagrada de gestar, e outra que ameaça as que fracassam na sua função de gerar filhos/as perfeitos/as e saudáveis. A partir desses discursos - do pré-natal, da medicina, das tecnologias, da nutrição, da educação física, da estética -, desencadeadores de aprendizagens corporais, é possível fazer referência a uma nova politização da maternidade: 
nova não no sentido de inovadora, mas no sentido de uma atualização, exacerbação, complexificação e multiplicação de investimentos educativo-assistenciais que têm como foco as mulheres (...) [no caso, as gestantes] (MEYER, 2004, p. 16).

Meyer (2004, p. 16) auxilia-nos a dizer que o processo da gravidez está estreitamente relacionado com o de construção de gênero: educar mulheres para tornarem-se grávidas e viverem como tal está dentro de processos que nos educam como sujeitos de gênero. Estar grávida, a nomeação é uma gestante é, ao mesmo tempo, o estabelecimento de uma fronteira e também a inculcação repetida de normas de como deve se comportar, cuidar. Normas que são incorporadas e difundidas por revistas, redes sociais, jornais, televisão, cinema, publicidade e pelo Estado, democratizando-se o modelo da "mãe cuidadosa" (SCHWENGBER, 2006).

Desenha-se na contemporaneidade uma detalhada administração da vida por meio de um complexo ordenamento de saberes e de práticas culturais que alimentam a compreensão de gerenciamento dos corpos das mulheres gestantes e os dos seres humanos que elas geram. Referimo-nos a esse processo em curso como politização dos corpos grávidos, uma vez que estão colocados "no centro das políticas de gestão da vida" (MEYER, 2004, p. 3).

Dessa forma, apoiamo-nos em um pressuposto feminista fundamental para o debate contemporâneo dos Estudos Feministas, na direção de pensar que o corpo é pessoal é também político. Nesse sentido, o que procuramos fazer aqui foi, então, evidenciar algumas dimensões de um movimento de significação muito mais amplo, no interior do qual uma multiplicidade de discursos, enunciados e imagens, como os da Pais \& Filhos, vem atuando e produzindo, investindo nas condições que estão na base dessa politização contemporânea do feminino e da maternidade.

\section{A POLITIZAÇÃO DA MATERNIDADE NO ÂMBITO DE POLÍTICAS CONTEMPORÂNEAS DE INCLUSÃO SOCIAL}

O interesse na produção da maternidade em um contexto cultural específico, ou seja, nas políticas contemporâneas de inclusão social, ${ }^{3}$ derivou do olhar sobre o Programa Nacional de Bolsa Escola (PNBE), com foco no que foi dito e veiculado sobre a maternidade nos documentos que o compunham. ${ }^{4}$ Considera-se que o Programa agregou

\footnotetext{
${ }^{3}$ Trata-se da pesquisa intitulada... Um cartão [que] mudou nossa vida? Maternidades veiculadas/instituídas pelo Programa Nacional Bolsa Escola (KLEIN, 2003).

${ }^{4}$ Atualmente, o PBF está representado por um guarda-chuva que abriga quatro programas sociais: o Bolsa Escola, o Cartão Alimentação, o Bolsa Alimentação e o Auxílio Gás. Tal como o Bolsa Escola, o PBF é um programa
} 
um extenso e importante conjunto de ações que, juntamente com outros programas elaborados e executados pelo governo Fernando Henrique Cardoso (1999-2003) para um segmento amplo da população, buscaram investir em uma política de distribuição de renda, aliando objetivos como a erradicação do trabalho infantil e o acesso à educação, ao mesmo tempo em que construíram significados para a maternidade. Vale dizer que o exame das políticas públicas voltadas para a educação e(m) saúde parte da compreensão de que elas educam, regulam e posicionam os sujeitos de gênero. Enquanto importantes instâncias pedagógicas, delineiam e constituem um determinado público-alvo, atuam na configuração de conceitos como infância, maternidade, família e juventude, além de investirem no âmbito das instituições familiar, escolar, pastoral e hospitalar, na assistência, por meio dos Centros de Referência de Assistência Social (CRAS), e na saúde, mediante as Unidades Básicas de Saúde (UBS), entre outras, visando à construção de comportamentos mais "saudáveis".

Algumas das principais compreensões desenvolvidas a partir desse estudo serviram como pressupostos para o desenvolvimento de outras investigações (KLEIN, 2010, 2015; 2018) e podem ser enumeradas: 1) os programas governamentais passam a ser tomados como aparatos culturais, enfocando não apenas o que foi/é dito e veiculado nos materiais, mas principalmente o modo como representações e discursos sobre maternidade e paternidade foram/são produzidos em nossa cultura; 2) por meio de políticas e programas governamentais, diferentes grupos expressam-se e buscam realizar seus projetos sociais, disputando sua visão de mundo e movimentando-se na construção de uma dada "realidade social brasileira", sendo que, para construir esse "real", precisam descrever, nomear e apresentar o que pretendem estabelecer como sendo o referente ou o ideal para a maternidade; 3) maternidade e paternidade tornam-se construtos socioculturais, resultantes de processos de (re)significação que não podem ser entendidos distantes das relações de poder que os constituíram/constituem, ou seja, como algo que não está inscrito na natureza feminina e/ou masculina, nem é proveniente de um suposto instinto biológico, inato e comum a todas as mulheres e a todos os homens; 4) as políticas públicas são visibilizadas a partir das argumentações em torno do processo de distribuição de renda e inclusão social, ou seja, a forma como investem e (re)constroem relações sociais generificadas, demarcando lugares, espaços e funções diferenciadas para homens e mulheres;

de transferência condicional de renda e alia o recebimento do dinheiro a compromissos com a educação e a saúde de crianças, adolescentes e gestantes (BRASIL, 2006). 
5) as análises das políticas públicas evidenciam formas de vincular as mulheres ao exercício da maternidade mediante o cumprimento de um conjunto de práticas, tais como ser fiscal da educação (e da saúde) das crianças e administrar a renda familiar, entre outras; 6) as políticas públicas dirigidas aos segmentos pobres e, nestes, preferencialmente às mulheres-mães tornam-se emblemáticas para compreendermos como as representações de mulher=mãe e mulher=família funcionaram e funcionam nesse contexto, delineando uma pedagogia que, ao educar mulheres como mães, as posiciona ao lado do Estado, corresponsabilizando-as pelo enfrentamento das questões estruturais da pobreza; 7) o exame desse material, exatamente por ele se inscrever em discursos que pretendem produzir uma determinada representação de mãe, evidencia pouco ou nenhum espaço reservado a considerações sociais ou culturais que possam impedir ou dificultar, por parte de algumas mulheres, o exercício da maternidade. O que tais discursos buscavam/buscam indicar é que ações políticas de distribuição de renda, de $100 \%$ das crianças na escola e de erradicação do trabalho infantil poderiam ser facilmente contornáveis, desde que houvesse/haja empenho, dedicação e vontade das mulheres e mães brasileiras; 8) o movimento de politização da maternidade foi/é acionado pela articulação entre os diferentes discursos que o PBE incorporou e fez funcionar quando propôs a inclusão social por meio da educação no Brasil contemporâneo; 9) a partir de uma perspectiva de gênero, em que se focaliza a construção tanto do feminino quanto do masculino, tornou-se possível discutir como ocorreu a obliteração da figura paterna. Se ela implica a incorporação da crítica feminista feita ao modelo de família mononuclear moderna, pode estar reforçando, também, a construção de uma masculinidade desobrigada de ocupar-se e responsabilizar-se pelos/as filhos/as que ajuda a gerar (KLEIN, 2003).

No delineamento das análises, as políticas públicas e programas governamentais foram/são tomados como biopolíticas voltadas à promoção e à produção da vida. A obra de Michel Foucault permite-nos discutir que é mediante as biopolíticas que se exerce o biopoder, em que as estratégias ${ }^{5}$ discursivas veiculadas por meio das políticas públicas passam a funcionar como uma "[...] forma de poder que regula a vida social, acompanhando-a, interpretando-a, absorvendo-a e a rearticulando", uma forma de poder que se exerce e “[...] só pode adquirir comando efetivo sobre a vida total da população

\footnotetext{
${ }^{5}$ Utilizamos a palavra estratégia no sentido indicado por Foucault, que corresponde "[...] ao conjunto dos meios operados para fazer funcionar um dispositivo de poder. Podemos também falar de estratégia própria às relações de poder na medida em que estas constituem modos de ação sobre a ação possível, eventual, suposta dos outros" (FOUCAULT, 1995, p. 248).
} 
quando se torna função integral, vital, que todos os indivíduos abraçam e reativam por sua própria vontade" (HARDT; NEGRI, 2004, p. 43).

Nesse sentido, o Primeira Infância Melhor (PIM) ${ }^{6}$ também se constituiu como importante corpus de investigação. Essa política está em vigência há 15 anos no estado do Rio Grande do Sul. ${ }^{7}$ Atualmente, articula-se às ações do Programa Criança Feliz $(\mathrm{PCF}),{ }^{8}$ de âmbito federal, e fundamenta-as. É assumida como:

Política pública pioneira no Brasil, o Primeira Infância Melhor (PIM) é uma ação transversal de promoção do desenvolvimento integral na primeira infância. Desenvolve-se através de visitas domiciliares e comunitárias realizadas semanalmente às famílias em situação de risco e vulnerabilidade social, visando o fortalecimento de suas competências para educar, proteger e cuidar suas crianças. (Perguntas e respostas... s/d)

Além disso, direciona-se à população com baixa escolaridade e renda - famílias com pouco acesso aos serviços públicos de educação, saúde e saneamento básico que residam em zonas rurais e/ou urbanas consideradas de risco ou em situação de vulnerabilidade social. O PIM atua como uma pedagogia cultural na construção de estratégias que tratam de associar, fundamentalmente, a educação das famílias pobres, por meio das mulheres-mães, à promoção da saúde infantil, pretendendo com isso também romper com o ciclo da pobreza no estado. Torna-se relevante indicar que os efeitos a partir do que é proposto nas políticas propagam-se não apenas ao público-alvo, a quem elas são endereçadas, mas também a gestores/as públicos/as, professores/as, visitadores/as e profissionais que atuam nas áreas da educação e saúde.

Ao assumirmos que somos sujeitos da linguagem e da cultura, tornou-se importante o exame dos documentos e das formas de interação propostas no âmbito da política, como constituídos e constituidores das práticas sociais. Explorou-se a metodologia que norteava as ações da política, além de ter sido realizado um trabalho de campo de cunho etnográfico. ${ }^{9}$ O objetivo foi compreender as formas

\footnotetext{
${ }^{6}$ O PIM foi lançado pelo então governador do estado do Rio Grande do Sul, Germano Rigotto, no dia 7 de abril de 2003, Dia Mundial da Saúde. Embasado na experiência teórico-metodológica do programa cubano Educa Tu Hijo, tornou-se política pública em 3 de julho de 2006, com a lei estadual n. 12.544/2006. Vale lembrar que o atual ministro do Desenvolvimento Social, Osmar Terra, foi Secretário de Saúde do Rio Grande do Sul nos governos Germano Rigotto (2003-2007) e Yeda Cruzius (2007-2011), período em que o PIM foi implantado como Programa e implementado como Política Pública neste estado.

7 "O PIM desde a assinatura do Marco Legal da Primeira Infância vem sendo citado como Modelo de Programa de Visitação Domiciliar com enfoque em Desenvolvimento Integral da Primeira Infância no país, sendo a principal inspiração para o Programa Nacional Criança Feliz." (Perguntas e respostas... s/d)

${ }^{8} \mathrm{O}$ atual Programa Criança Feliz (PCF) “[...] é um programa do governo federal e foi instituído por meio do Decreto $\mathrm{n}^{\circ} 8.869$, de 05 de outubro de 2016, tendo como fundamento a Lei ${ }^{\circ} 13.257$, de 08 de março de 2016, que trata do Marco Legal da Primeira Infância. A primeira infância é o período que abrange os seis primeiros anos completos, ou seja, os 72 meses de vida da criança." (BRASIL, 2017, p. 9)

9 O trabalho de campo foi realizado no município de Canoas/RS ao longo de 11 meses - de março de 2007 a janeiro de 2008 -, abrangendo observação e registro das atividades referentes ao PIM e, ainda, seleção e análise dos documentos oficiais.
} 
de ensinar/posicionar as mulheres a tornarem-se mães de determinados tipos, acompanhando o trabalho da equipe de técnicos em encontros semanais e o das visitadoras nas residências. Tal imersão permitiu dizer que grande parte das políticas de inclusão social e/ou educação e(m) saúde postula o desenvolvimento infantil saudável pautado, principalmente, nos discursos científicos, como os da puericultura, da medicina, da psicologia e da neurociência. Com isso, produzem-se formas de intervenção dirigidas às famílias, além de ser possível contribuir para a redução dos índices de violência, desigualdade, fracasso escolar e exclusão social. Argumentamos que um detalhado aparato pedagógico voltado ao desenvolvimento infantil saudável, por meio do PIM, pretendeu/pretende constituir importantes espaços de veiculação e articulação de estratégias educativas dirigidas aos/às profissionais da educação e da saúde com as famílias-alvo, mas, sobretudo, educando as mulheres-mães pobres. Isso ocorre não só por meio da elaboração de campanhas, anúncios televisivos e folders, mas também pelo uso sistemático de cartilhas, cadernetas e guias endereçados às famílias e aos/às visitadores/as, ${ }^{10}$ bem como mediante capacitações, visitas domiciliares e reuniões grupais e comunitárias (KLEIN, 2018).

Ocorre no âmbito do PIM, assim como no atual PCF, a formação de um "currículo" específico, incorporando e veiculando estratégias educativas voltadas ao posicionamento das mulheres como mães amorosas, cuidadoras, nutrizes e promotoras do desenvolvimento infantil saudável, tornando-as capazes de realizar tarefas relacionadas com a organização doméstica, higiene, estimulação, alimentação, educação e saúde. São principalmente as mulheres pobres que nesses contextos necessitam aprender e responsabilizar-se, no centro das políticas de gestão da vida, como as principais agentes de inclusão social ao assumirem e cumprirem objetivos e metas sociais amplas, que devem ser problematizados (KLEIN e MEYER, 2018).

No centro desse currículo específico, da organização do trabalho sistemático, do planejamento, da avaliação e realização das atividades de educação e(m) saúde, evidenciava-se um (dado) conhecimento voltado ao desenvolvimento infantil e à família, disposto e difundido a partir de regras universais e aplicáveis a todos os indivíduos. Os/as técnicos/as, visitadoras, mas fundamentalmente as mulheres-mães, tornam-se alvos privilegiados, a fim de difundir tal conhecimento e incorporá-lo, por meio de tarefas, brincadeiras, histórias, gestos de amor, desafios e estímulos

\footnotetext{
${ }^{10}$ Caderneta da Criança, Caderneta da Criança e do Adolescente, Caderneta da Gestante, Guia da Gestante, Guia da Família, Guia de Orientação para GTM, Monitor e Visitador.
} 
para cada fase do desenvolvimento, ou seja, ações "naturalmente" vinculadas à maternidade. Desse modo, ao legitimarem-se aspectos da maternidade calcados no corpo e na biologia, desconsideram-se, na maior parte das vezes, as dimensões sociais, culturais e políticas que envolvem e atravessam esses processos.

Argumentamos que os conhecimentos que embasam as propostas da política aqui abordada se tornam elementares para a produção de raciocínios generificados, ${ }^{11}$ essenciais ao feminino e à maternidade, posicionando as mulheres-mães como cuidadoras e protetoras, o que necessita ser assumido, inclusive, por técnicos/as e visitadoras. Vale ressaltar que, no centro das políticas de gestão da vida, os currículos, as instituições, as avaliações, as teorias, a saúde, o cuidado, os comportamentos, os espaços, as normas, os símbolos, as leis, os serviços assistenciais e as políticas públicas tornam-se generificados.

\section{COSTURANDO A SÍNTESE DE UM LEGADO}

Ao alinhavarmos essa proposição, na perspectiva de finalizar temporariamente este artigo, recorremos à definição de legado "como uma disposição feita, um testemunho para benefício de outra [...] a transmissão de alguma coisa [...] [ou ainda] um legado [que] pode ser constituído por alguma coisa imaterial” (AURÉLIO, 2018). Tomamos o conceito da politização da maternidade, então, como um forte legado cultural e político que ainda está longe de ser explorado no cenário atual, utilizando-o como forma de resistência, perturbação e questionamento de algumas formas vigentes de medicalização, educação, controle, beleza e promoção da saúde, por exemplo.

A palavra legado é proveniente do latim legatos, que, por sua vez, é derivada de legare, ou delegar. Em um sentido mais aprofundado, pode significar aquele a quem deu. Assim, tomamos o conceito da politização da maternidade de Meyer como um legado capaz de fornecer "pistas" valiosas, linhas de partida, princípios orientadores para gestar e construir nossas estratégias mobilizadoras de pesquisa.

O intuito deste artigo foi demonstrar a relevância da produção de Meyer, que contribuiu tanto para as pesquisas aqui citadas, quanto para o movimento feminista, os estudos de gênero e a problematização da educação e do governo das mulheres. Ao atentar para a universalidade do conceito de mãe ideal na mentalidade histórica, especialmente no Brasil, Meyer (2005; 2006) tem atuado para uma elaboração

\footnotetext{
${ }^{11}$ Walkerdine (1995), Paraíso (2011).
} 
epistemológica sobre a maternidade, propondo-se a desnaturalizar estratégias discursivas que coloquem em ação o cuidado como função exclusiva das mulheres e a maternidade como uma obrigação social e compulsória.

Meyer $(2005$; 2006) insiste que a maternidade seja reconhecida, analisada e problematizada em meio à sua produção e dispersão, aliada aos múltiplos jogos de força e de poder e instituída a partir de significados políticos. Ainda, para Meyer, a maternidade geralmente é abordada como uma função ou um papel social, havendo um grande silenciamento teórico sobre os sentimentos pelos quais passam as mulheres que experimentam em seus corpos a gestação, o nascimento, a nutrição e os cuidados de uma criança, dentre outros aspectos relacionados à experiência da maternidade. A sua crítica torna-se contundentemente política e interessada ao encaminhar-nos ao exame da cultura, fundamentalmente, por meio dos processos constitutivos que têm colocado as mulheres, os seus corpos e a maternidade no centro dos debates políticos contemporâneos, tal como buscamos evidenciar na Pais \& Filhos e nas políticas de inclusão social.

Podemos dizer que a autora propõe, no âmbito do GEERGE, assim como nos Estudos de Gênero, uma "poética da maternidade" mais rica de sentidos, instável, polissêmica e até ambivalente, tornando-a menos mitificada, patriarcal e estável, conforme destaca em seus estudos há décadas. O legado de Meyer tem nos fornecido um material desafiador para pensarmos em novas possibilidades de viver a maternidade e a configuração de arranjos e relações familiares, movimentando, pondo sob suspeita e desafiando compreensões e conceitos fixos e tradicionais.

A produção de Meyer tem sido encarada por nós como um convite para pensarmos no potencial político das instabilidades em torno da maternidade, ao invés de um modelo teórico a ser seguido. Para Meyer (2003), na atualidade, os corpos femininos e a maternidade tornam-se centrais nos debates públicos, cabendo à academia (em particular, às estudiosas feministas) compreender como isso se dá e com que efeitos. O exercício da maternidade se produz e se modifica na cultura (MEYER, 2006), e é justamente por isso que cabem o exame dos processos educativos e de produção da maternidade, o alargamento de seus sentidos, assim como sua historicização estratégias necessárias, uma vez que nos possibilitam evidenciar como determinadas maternidades são significadas politicamente no interior de uma série de discursos e saberes que as normatizam e definem. 


\section{REFERÊNCIAS}

AURÉLIO, Dicionário On-line. Legado. Disponível em: https://dicionariodoaurelio.com/espraiar. Acesso em: 10 março 2018.

BRASIL. Estatuto da criança $\boldsymbol{e}$ do adolescente (1990). Estatuto da criança e do adolescente: Lei n. 8.069, de 13 de julho de 1990, Lei n. 8.242, de 12 de outubro de 1991. - 3. ed. - Brasília: Câmara dos Deputados, Coordenação de Publicações, 2001.

BUTLER, Judith. Problemas de gênero: feminismo e subversão da identidade. 3a ed. Rio de Janeiro: Civilização Brasileira. 2010.

FISCHER, Rosa Maria Bueno. Problematizações sobre o exercício de ver: mídia e pesquisa em educação. Revista Brasileira de Educação, Campinas: Editores Associados/AMPED, n. 20, maio./jun./jul./ago. 2002.

FOUCAULT, Michel. A arqueologia do saber. Rio de Janeiro: Foerense, 1993.

FRAGA, Alex Branco. Exercício da informação: governo dos corpos no mercado da vida ativa. Tese de Doutorado, Programa de Pós-Graduação em educação. Universidade Federal do Rio Grande do Sul, 2005.

KLEIN, Carin. Biopolíticas de inclusão social e produção de maternidades e paternidades para uma "infância melhor". Tese de doutorado, Educação, UFRGS, 2010. KLEIN, Carin. Discursos que concorrem para a produção de infância e maternidade em políticas de inclusão social. Textura, Canoas, v. 20, n. 43, p. 53-78, mai.-ago. 2018.

KLEIN, Carin; MEYER, Dagmar Estermann. Pedagogias da maternidade no âmbito da Política Primeira Infância Melhor/RS. Teias, ProPED, UERJ. jul.-set. 2018. No prelo.

MEYER, Dagmar Estermann. Corpo, saúde e gênero: fragmentos de histórias sobre corpos e vidas maternas. In: TORNQUIST, Carmen et al. (org.). Leituras de resistência: corpo, violência e poder. vol. II. Florianópolis, Ed. Mulheres, 2009, p. 81-103.

MEYER, Dagmar Estermann. Educação, saúde e politização da maternidade: Olhares desde a articulação entre estudos culturais e estudos de gênero. In. SILVEIRA, Rosa Maria Hessel. (org.). Cultura, poder e educação: um debate sobre estudos culturais em educação. Canoas: Ed. ULBRA, 2005, p. 145-163.

MEYER, Dagmar Estermann. Educação, saúde e modos de inscrever uma forma de maternidade nos corpos femininos. Movimento, Porto Alegre, v. 9, n. 3, p. 38-52, 2003.

MEYER, Dagmar. A politização contemporânea da modernidade. Gênero: núcleo transdisciplinar de estudos de gênero - NUTEG, Niterói, v. 6, n. 1, 2006.

A educação da família como estratégia governamental de inclusão social: um estudo situado na interface dos Estudos Culturais, de Gênero e de Vulnerabilidade. Projeto CNPQ. Porto Alegre: UFRGS/FACED, 2004a.

Direitos reprodutivos e educação para o exercício da cidadania reprodutiva: perspectivas e desafios. In: FONSECA, Claudia; TERTO, Veriano; ALVES, Calef, (Orgs). Antropologia, diversidade e direitos humanos: diálogos interdisciplinares Porto Alegre: UFRGS, 2004b.

Gênero e Educação: teoria e política. In: LOURO, Guacira; NECKEL, Jane Felipe. Petrópolis: Vozes, 2003a.

. Educação, saúde e modos de inscrever uma forma de maternidade nos corpos femininos. Revista movimento, Porto Alegre, v. 9, n. 3, p. 38-52, 2003 b. 
Educar e assistir corpos grávidos para gerar e criar seres humanos "saudáveis". Educação, saúde e constituição de sujeito "de direito" e "de risco". Porto Alegre: UFRGRS/FACED, 2002a (Projeto de pesquisa).

Pedagogias do Aleitamento Materno. Educação, saúde e produção de identidades de gênero. Porto Alegre: UFRGS/FAPERGS, 2002. Relatório de Pesquisa. Faculdade de Educação da UFRGS/Fundação de Amparo à Pesquisa do Estado do Rio Grande do Sul, 2002b.

As mamas como constituintes da maternidade: uma história do passado. Educação e Realidade, Porto Alegre, v. 25, n. 2, jul./dez., 2000.

MIRA, Maria Celeste. O leitor e a banca de revistas: a segmentação da cultura no Século XX. São Paulo: Olho D’Água/FAPESP, 2001.

PARAÍSO, Marlucy. Raciocínios genereficados no currículo escolar e possibilidades de aprender. In: LEITE, Carlinda et al. (org.). Políticas, fundamentos e práticas do currículo. Porto, Porto Editora, 2011, p.147-160.

RIO GRANDE DO SUL, Secretária Estadual da Saúde. Programa Primeira Infância Melhor. Pressupostos Teóricos. Disponível em: http://www.pim.saude.rs.gov.br/v2/opim/pressupostos-teoricos/s/d a. Acesso em: 13 abr. 2018.

RIO GRANDE DO SUL, Secretária Estadual da Saúde. Programa Primeira Infância Melhor. Programa Criança Feliz no RS. Disponível em: http://www.pim.saude.rs. gov.br/v2/programa-crianca-feliz-no-rs/s/db. Acesso em: 13 abr. 2018.

RIO GRANDE DO SUL, Secretaria da Saúde, Programa Primeira Infância Melhor,

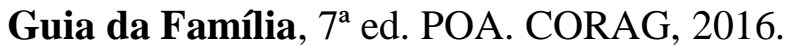

RIO GRANDE DO SUL, Secretaria da Saúde, Programa Primeira Infância Melhor, Guia da Gestante, $7^{\mathrm{a}}$ ed. POA. CORAG, 2016b. 76 p.

Secretaria da Saúde do Estado do Rio Grande do Sul. Programa Primeira Infância Melhor. Guia de Orientação para GTM, Monitor e Visitador. Contribuições para políticas na área do desenvolvimento infantil. Porto Alegre: Relâmpago, 2007. 70 p.

SCHWENGBER, M. S. V. Donas de si? a educação de corpos grávidos no contexto da Pais \& Filhos. 2006. 192 f. Tese. (Doutorado em Educação) - Faculdade de Educação, Universidade Federal Rio Grande do Sul, 2006.

WALKERDINE, Valerie. O raciocínio em tempos pós-modernos. Educação \& Realidade 20 (2), Porto Alegre, 1995, pp. 207-226.

YALOM, Marilyn. A história do seio. Lisboa: Teorema, 1997.

Referências dos excertos

Pais \& Filhos, São Paulo, n. 253, p. 21, jan. 1990.

Pais \& Filhos, São Paulo, p. 76, jun. 1974. 